\author{
Asian Journal of \\ Medical and Biological Research \\ ISSN 2411-4472 (Print) 2412-5571 (Online) \\ www.ebupress.com/journal/ajmbr
}

\title{
Article \\ Prevalence and antibiotic susceptibility pattern of pathogens from urinary tract infections (UTI) in a private diagnostic laboratory in Bangladesh
}

\author{
Md. Habibur Rahman ${ }^{1 *}$, Mushtaque Ahmed ${ }^{2}$, Dayanidhi Sarkar ${ }^{3}$ and Md. Asadur Rahman ${ }^{4}$ \\ ${ }^{1}$ Microbiologist, Dept. of Microbiology, Popular diagnostic centre ltd. Dhaka, Bangladesh \\ ${ }^{2}$ Professor, Dept. Microbiology, Popular Medical College, Dhaka, Bangladesh \\ ${ }^{3}$ Assistant Professor, Dept. Microbiology, Primeasia University, Banani, Dhaka, Bangladesh \\ ${ }^{4}$ Jr. Consultant, Dept. of Immunology, Popular diagnostic centre Itd. Dhaka, Bangladesh
}

*Corresponding author: Md. Habibur Rahman, Microbiologist, Dept. of Microbiology, Popular Diagnostic Centre Ltd. 11, Shantinagar (Popular Tower), Dhaka, Bangladesh. Phone: +8801717836069; E-mail: habiburmi333231@gmail.com

Received: 05 September 2020/Accepted: 24 September 2020/ Published: 30 September 2020

\begin{abstract}
Urinary tract infection (UTI) is one of the commonest infections encountered by clinicians and despite the widespread availability of antimicrobial agents UTI has become difficult to treat because of appearance pathogens with increasing resistance to antimicrobial agents. The aim and objectives of this study were to determine the pathogens causing UTI and to determine the antibiotic sensitivity status among these isolates in a diagnostic laboratory in Dhaka city. A laboratory based cross sectional survey was conducted in Popular Diagnostic Centre Ltd. Dhanmondi, Dhaka-1205, Bangladesh from July 2016 to December 2016. A total of 553 freshly voided midstream urine samples $(10-20 \mathrm{ml})$ were collected in a wide mouth sterile container from patients and processed in microbiology laboratory to isolate pathogens and antibiotic susceptibility test using standard procedure. Among 553 urine sample, the culture positivity in urine samples was found to be 158 $(28.57 \%)$ of which $39(24.70 \%)$ were isolated from male patients and $119(75.30 \%)$ from female patients. Escherichia coli $(43.67 \%)$ were found to be the predominant pathogen followed by Staphylococcus spp. (16.45\%), Enterococcus spp. (13.39\%), Klebsiella spp. (13.29\%), Candida spp. (5.70\%), Acinetobacter spp. (4.43\%), Psudomonas spp. (3.80\%) and Proteus spp. (1.27\%). Carbapenem group (Imipenem, Meropenem) were the most effective antibiotic with resistance between 0 and $5.1 \%$ of the gram negative isolates and Linezolid and Vancomycin was most effective in gram positive isolates. Nitrofurantoin was most effective both gram negative and gram positive isolates. This study finding showed That Escherichia. coli isolates were the predominant pathogens and showed increasing pattern to the commonly prescribed drugs in private practice that in turn leaves the clinicians with very few alternative options in drug for the treatment of UTIs.
\end{abstract}

Keywords: urinary tract infection (UTI); uropathogens; antimicrobial susceptibility; antimicrobial agents

\section{Introduction}

Urinary tract infection (UTI) is the common bacterial infectious disease in community practice with high rate of morbidity and financial cost all over the world. Worldwide, about 150 million people are suffering from UTI/year, costing 6 billion US dollar (Gonzalez et al., 1999). Nearly about 10\% of people will experience in UTI during lifetime (Hoberman et al., 1997). UTIs refer to the presence of microbial pathogens within the urinary tract and it is usually classified by the site of infection of urinary bladder (cystitis), kidney (pyelonephritis) or urine (bacteriuria). Almost 95\% of cases of UTI are caused by bacteria that typically multiply at the opening of the urethra and travel up to the bladder.

A limited predictable spectrum of organism is responsible for urinary tract infection. Most of the UTI are caused by gram negative bacteria like Esherichia coli, Klebsiella spp., Pseudomonas aeruginosa, Proteus spp., Acinetobacter spp., Serratia and Morganella margani. 
UTI also caused by Gram positive bacteria like Enterococcus spp., Staphylococcus especially coagulase negative Staphylococci and Streptococcus agalactiae (Shaaban et al., 2012). UTI is much more common in Women than in men due to anatomical and physiological reason; by virtue of its position urogenital tract is more vulnerable to bacterial infection caused by internal and external flora.

Studies from India, Navaneeth et al., 2002, Bangladesh, Iqbal et al., 1997 and Nepal, Srinivassa et al., 199 have reported an increased resistance of the urinary pathogens to commonly used antibiotics. The aim of this study was to determine microbial etiologic agents responsible for urinary tract infection and to evaluate them in vitro susceptibility pattern to commonly used antimicrobial agents in a private practice set up of Dhaka city. This study is important for clinicians in order to facilitate the effective treatment and management of patients with symptoms of urinary tract infection.

\section{Materials and Methods}

\subsection{Study design}

A prospective cross-sectional study was conducted in the dept. of Microbiology, Popular Diagnostic Centre Ltd. Dhaka, Bangladesh. Total 553 samples were collected during this study period from July 2016 - Dec 2016.

\subsection{Inclusion/Exclusion criteria}

Study population consisted of all the patients who visited the concerned laboratory for urine culture examination.

\subsection{Sample collection and processing}

Study population were instructed on how to collect clean-catch mid-stream urine into sterile container after carefully cleaning the genitalia, especially around the opening the urethra. Samples were collected wide mouthed, leak proof container supplied by the laboratory and brought to the laboratory as early as possible, usually within 1 hour after collection.

\subsection{Microscopy}

The urine samples were mixed thoroughly, centrifuged and examined microscopically for wet mount preparation.

\subsection{Culture}

A calibrated sterile Nicrome wire loop for the semi-quantitative method was used for the plating. It has a $4 \mathrm{~mm}$ diameter to deliver $0.01 \mathrm{ml}$. A loopful of the well mixed urine sample was inoculated on Hi-Chrome (Himedia, India), MacConkey and Blood agar media (Mast diagnostic, UK) and then incubated at $37^{\circ} \mathrm{C}$ aerobically for 24 hrs and for $48 \mathrm{hrs}$ in negative cases.

They were then examined for bacterial growth. A significant bacterial count was taken as any count equal to or in excess of 100,000 CFU/ml. A less than $100 \mathrm{CFU} / \mathrm{ml}$ was interpreted as negative.

\subsubsection{Cultural observation}

Color, size, and colony morphology are observed from the incubated plates.

\subsubsection{Microscopic examination of pathogens}

Slides were prepared from each different colonies observed on the plates and gram staining was performed. The results such as the gram positive or gram negative, shape of the bacteria are observed from the examinations.

\subsection{Biochemical examination}

The selected colonies based on the cultural, microscopic and microbiological examinations, were subjected to biochemical examination (starch hydrolysis, lipid hydrolysis, casein hydrolysis, triple sugar iron agar test, oxidase test, catalase test, nitrate reduction test, indole production test, methyl red test, voges-proskauer test, citrate utilization test, urease test) for confirmation of the pathogens (Cheesbrough, 2006).

\subsection{Antibiotic susceptibility testing}

In the present study antimicrobial susceptibility testing was done on Mueller-Hinton agar media (Mast diagnostic, UK) using disk diffusion (Kirby Bauer's) method according to the Clinical Laboratory Standard Institute (CLSI) guidelines using the following antimicrobial agents: Ampicillin $10 \mu \mathrm{g}$, Amikacin $30 \mu \mathrm{g}$, Aztreonam $30 \mu \mathrm{g}$, Cefepime $30 \mu \mathrm{g}$, Ceftriaxone $30 \mu \mathrm{g}$, Ceftazidime $30 \mu \mathrm{g}$, Cefixime $5 \mu \mathrm{g}$, Cefoxitin $30 \mu \mathrm{g}$, 
Cloxacillin $5 \mu \mathrm{g}$, Cotrimoxazole $25 \mu \mathrm{g}$, Ciprofloxacin $5 \mu \mathrm{g}$, Imipenem $10 \mu \mathrm{g}$, Gentamicin $10 \mu \mathrm{g}$, Meropenem $10 \mu \mathrm{g}$, Netilmicin $30 \mu \mathrm{g}$, Nitrofutantion $300 \mu \mathrm{g}$, Levofloxacin $5 \mu \mathrm{g}$ Vancomycin $30 \mu \mathrm{g}$, Linezolid $30 \mu \mathrm{g}$, Netilmicin $30 \mu \mathrm{g}$, Penicillin $10 \mu \mathrm{g}$. Reference strains of E. coli ATCC 25922 and S. aureus ATCC 25923 were used for quality control for antimicrobial susceptibility tests (CLSI, 2014).

\subsection{Statistical analysis}

The statistical analysis of data was performed using Microsoft Excell-2011 version. Discrete values were expressed as percentage. Descriptive statistics were used to summarize patient characteristics and the prevalence of antimicrobial sensitivity.

\section{Results}

Out of 553 urine samples, the culture positive $\left(\geq 10^{5} \mathrm{cfu} / \mathrm{ml}\right)$ was found $158(28.57 \%)$ of which $39(24.70 \%)$ were isolated from male patients and 119 (75.30\%) from female patients and other $395(71.43 \%)$ sample were negative or normal flora (Table 1).

Table 1. Growth of urine culture among the study population $(n=553)$.

\begin{tabular}{llll}
\hline Culture & Frequency (\%) & Male (\%) & Female (\%) \\
\hline Positive & $158(28.57)$ & $39(24.68)$ & $119(75.32)$ \\
Negative & $395(71.43)$ & $155(39.00)$ & $241(61.00)$ \\
Total & $553(100)$ & $194(35.00)$ & $360(65.00)$ \\
\hline
\end{tabular}

Most of the patients were in age group of 21 to 40 years, which were $38(17.92 \%)$ cases positive; among them $34(98.12 \%)$ were female and $4(1.88 \%)$ cases were male. In the age group of less than 20 years' female is also predominant than male which is $16(61.54 \%)$ cases and $10(38.46 \%)$ cases respectively. Overall female was more common than male, shown in Table 2.

Table 2. Age and sex distribution of positive patient $(n=158)$.

\begin{tabular}{lllll}
\hline Age & No & Growth $(\boldsymbol{\%})$ & Female (\%) & Male (\%) \\
\hline$<20$ & 105 & $26(24.76)$ & $16(61.54)$ & $10(38.46)$ \\
$21-40$ & 212 & $38(17.92)$ & $34(98.12)$ & $4(1.88)$ \\
$41-60$ & 152 & $60(39.47)$ & $48(80.00)$ & $12(20.00)$ \\
$61-80$ & 77 & $29(37.66)$ & $19(65.52)$ & $10(34.48)$ \\
$>80$ & 7 & $5(71.42)$ & $2(40.00)$ & $3(60.00)$ \\
\hline
\end{tabular}

The most common isolates in this study have been the gram negative bacilli which accounts for $66.45 \%$ of the total positive isolates. In the gram negative bacilli, the predominant isolate was the E. coli $(43.96 \%)$ followed by other bacilli like Klebsiella spp. (13.29\%), Acinetobacter spp. (4.43\%), Pseudomonas spp. (3.80\%) and Proteus spp. (1.27\%) among the major isolates (Table 3). In gram positive organism identified was $27.85 \%$ which is followed by Staphylococcus spp. (16.45\%) and Enterococcus spp. (13.39\%). Candida spp. was responsible for $(5.70 \%)$ of cases (Table 3$)$.

Table 3. Frequency of positive isolates with based on sex.

\begin{tabular}{|c|c|c|c|c|}
\hline Name of the isolates & & Frequency (\%) & Male (\%) & Female (\%) \\
\hline \multirow{5}{*}{$\begin{array}{l}\text { Gram negative } \\
(\mathrm{N}=105)\end{array}$} & E. coli & $69(43.67 \%)$ & $\mathbf{1 6}(10.12 \%)$ & $53(33.55 \%)$ \\
\hline & Klebsiella spp. & $21(13.29 \%)$ & $3(1.90 \%)$ & $18(11.39 \%)$ \\
\hline & Acinetobacter spp. & $7(4.43 \%)$ & $2(1.27 \%)$ & $5(3.16 \%)$ \\
\hline & Pseudomonas spp. & $6(3.80 \%)$ & $3(1.90 \%)$ & $3(1.90 \%)$ \\
\hline & Proteus spp. & $2(1.27 \%)$ & $1(0.63 \%)$ & $1(0.63 \%)$ \\
\hline \multirow{2}{*}{$\begin{array}{l}\text { Gram positive } \\
(\mathrm{N}=44)\end{array}$} & Staphylococcus spp. & $26(16.45 \%)$ & $8(5.06 \%)$ & $18(11.39 \%)$ \\
\hline & Enterococcus spp. & $\mathbf{1 8}(13.39 \%)$ & $3(1.90 \%)$ & $15(9.50 \%)$ \\
\hline \multirow[t]{2}{*}{ Fungus $(\mathrm{N}=9)$} & Candida spp. & $9(5.70 \%)$ & $3(1.90 \%)$ & $6(3.80 \%)$ \\
\hline & & $158(100 \%)$ & $39(24.68 \%)$ & $119(75.32 \%)$ \\
\hline
\end{tabular}


Table 4. Distribution of antibiotic sensitivity among the bacterial isolates.

\begin{tabular}{|c|c|c|c|c|c|c|c|}
\hline \multirow{3}{*}{$\begin{array}{l}\text { Antibiotic } \\
\text { Susceptibility }\end{array}$} & \multicolumn{5}{|c|}{ Gram negative isolates } & \multicolumn{2}{|c|}{ Gram positive isolates } \\
\hline & E. coli & Klebsiella & Acinetobacter & Pseudomonas & Proteus & Staphyloccus & Enterococcus \\
\hline & $\mathrm{n}=69(\%)$ & $\mathrm{n}=21(\%)$ & $\mathrm{n}=7(\%)$ & $\mathrm{n}=6(\%)$ & $\mathrm{n}=2(\%)$ & $\mathrm{n}=26(\%)$ & $\mathrm{n}=\mathbf{1 8}(\%)$ \\
\hline Ampicillin & $3(4.34)$ & $3(14.28)$ & $0(0.00)$ & $0(0.00)$ & $0(0.00)$ & $2(7.69)$ & $16(88.88)$ \\
\hline Cephradine & $6(8.69)$ & $5(23.80)$ & $0(0.00)$ & $0(0.00)$ & $1(50.00)$ & - & - \\
\hline Cefriaxone & $21(30.43)$ & $14(66.66)$ & $2(28.57)$ & $2(33.33)$ & $1(50.00)$ & - & - \\
\hline Cefixime & $20(28.98)$ & $12(57.14)$ & $1(14.28)$ & $0(0.00)$ & $1(50.00)$ & - & - \\
\hline Ceftazidime & $43(62.31)$ & $15(71.42)$ & $3(42.85)$ & $3(50.00)$ & $2(100.0)$ & - & - \\
\hline Cefepime & $47(68.11)$ & $16(76.19)$ & $4(57.14)$ & $4(66.66)$ & $2(100.0)$ & - & - \\
\hline Imipenem, & $65(94.20)$ & $20(95.23)$ & $6(85.71)$ & $5(83.33)$ & $2(100.0)$ & $25(96.15)$ & $16(88.88)$ \\
\hline Meropenem & $65(94.20)$ & $20(95.23)$ & $6(85.71)$ & $5(83.33)$ & $2(100.0)$ & $25(96.15)$ & $16(88.88)$ \\
\hline Cotrimoxazole & $26(37.63)$ & $10(47.61)$ & $1(14.28)$ & $0(0.00)$ & $1(50.00)$ & $12(46.15)$ & - \\
\hline Gentamycin & $53(76.81)$ & $16(76.19)$ & $5(71.42)$ & $4(66.66)$ & $2(100.0)$ & $22(84.61)$ & - \\
\hline Netilmicin & $58(84.05)$ & $17(80.95)$ & $5(71.42)$ & $5(83.33)$ & $2(100.0)$ & $23(88.46)$ & - \\
\hline Amikacin & $62(89.85)$ & $19(90.47)$ & $6(85.71)$ & $5(83.33)$ & $2(100.0)$ & $24(92.30)$ & - \\
\hline Ciprofloxacin & $27(39.13)$ & $12(57.14)$ & $2(28.57)$ & $2(33.33)$ & $1(50.00)$ & 11(42.30) & $12(66.66)$ \\
\hline Levofloxacin & $30(43.47)$ & $12(57.14)$ & $2(28.57)$ & $2(33.33)$ & $1(50.00)$ & $12(46.15)$ & $12(66.66)$ \\
\hline Doxycycline & $13(18.84)$ & $8(38.09)$ & $0(0.00)$ & $0(0.00)$ & $0(0.00)$ & $9(34.61)$ & $13(72.22)$ \\
\hline Tertracycline & $13(18.84)$ & $8(38.09)$ & $0(0.00)$ & $0(0.00)$ & $0(0.00)$ & $9(34.61)$ & $13(72.22)$ \\
\hline Nitrofurantoin & $61(88.40)$ & $13(61.90)$ & $6(85.71)$ & $4(66.66)$ & $2(100.0)$ & $22(84.61)$ & $16(88.88)$ \\
\hline Aztreonam & $36(52.17)$ & $13(61.90)$ & $4(57.14)$ & $3(50.00)$ & $2(100.0)$ & - & - \\
\hline Cefoxitin & $53(76.81)$ & 17(76.19) & $5(71.42)$ & $4(66.66)$ & $2(100.0)$ & $18(69.23)$ & - \\
\hline Cloxacillin & - & - & - & - & - & $18(69.23)$ & - \\
\hline Tigecycline & - & - & - & - & - & $26(100.0)$ & $18(100.0)$ \\
\hline Lenizolid & - & - & - & - & - & $26(100.0)$ & $18(100.0)$ \\
\hline Vancomycin & - & - & - & - & - & $24(92.30)$ & $16(88.88)$ \\
\hline
\end{tabular}

\section{Discussion}

This study provides valuable data to isolate and identify the pathogen which cause urinary tract infection and monitor the status of antimicrobial sensitivity among uropathogens to improve efficient empirical treatment. In addition to that the susceptibility pattern of these bacteria is very important to avoid development of drug resistant (Behzadi et al., 2010). In our study isolation \& identification of uropathogens were performed and $158(28.57 \%)$ urine sample showed significant growth of bacteria so, remaining majority $395(71.43 \%)$ of the cases showed either insignificant bacteriuria or no growth with urine from the suspected cases of UTI.

This study resembles to the study conducted by Yusuf et al., 2015 and Barber et al., 2013 and they showed 28\% significant bacterial growth.

The reason of low growth rate may be due to irrational use of antibiotic which is available in the local market in this country and these are given without prior culture and antibiotic sensitivity pattern. In addition to that, incomplete doses are another factor. Prior antibiotic therapy before sending urine sample for culture and sensitivity and other clinical conditions like non-gonococcal urethritis could be the factors responsible for insignificant bacteriuria or no growth. (Barber et al., 2013).

In this study showed the prevalence was high in females than males for each isolates $75.31 \%$ and $24.68 \%$ respectively, so we can say strictly female suffers more than male from UTI. Other studies also showed that urinary tract infection was more common females. Akhter et al., 2012 and Yusuf et al., 2015 was found $71.6 \%$ and $66.6 \%$ respectively.

It is well established that female is more commonly infected with UTI than male due to anatomical position of urethra, influence of hormone and pregnancy (Jones et al., 1999) The international studies have shown that UTIs in women are very common; therefore, one in five adult women experience UTI in her life and it is extremely common, clinically apparent, worldwide patient problem.

The most frequently isolated species was E. coli $43.67 \%$ followed by Staphylococcus spp. 16.45\%, Enterococcus spp. $13.39 \%$, Klebsiella spp. 13.29\%, Acinetobacter spp. 4.43\%), Candida spp. 5.70\%, Psudomonas spp. 3.80\% and Proteus spp. 1\%. These results agree with Alshwaikh et al., 2014 who found that E. coli (46.66\%) followed by Staphylococcus spp. (15.8\%), and also agree with Shaaban et al., 2012 who found that E. coli $43 \%$ followed by Klebsiella pneumonia 14.1\%, Pseudomonas aeruginosa and Proteus mirabilis $9.4 \%$.

Among the different uropathogens, the most predominant organism was found to be E. coli $43.67 \%$, which is confirmed to the study done by Oluremi et al., 2011 and also in study conducted by Chakupurakal et al., 2010 
where predominant organism was E. coli and in number of reports worldwide where the particular organisms is identified as most common uropathogens. The dominance of E. coli is followed by Staphylococcus spp. 16.45\% in this study resembles to the study done by Jha et al., 2005 which was the second most organisms causing UTI. In sectional study by University of Florida USA of a group of patient, 81 patients met the inclusion criteria of this study of these 81 patients $89 \%$ had UTI E. coli (Mcloughlin et al., 2003).

Antibiotic susceptibility test reveals that higher percentage of susceptibility for Imipenem \& Meropenem $96 \%$, followed by Nitrofurantoin (88\%), Amikacin (88\%), Netilmicin (88\%), shown in Table 4. This study resembles to the study conducted by Farjana et al., 2009 where higher percentage of susceptibility was seen for amikacin $(88 \%)$. Second is the nitrofurantoin which considered as an appropriate agent for first line treatment of community acquired UTIs.

Ampicillin was found to show the higher resistance rate $(98 \%)$ which resembles to the study conducted by Nerukar et al., 2012 which show that isolates of most of the species exhibited a high rate of resistance to ampicillin. Resistance to antibiotics develops due to its frequent misuse. (Nerukar et al., 2012)

According to the above result, among antibiotics used for susceptibility test for gram negative bacteria, amikacin, netilmicin, and nitrofurantoin was found to be the most effective antibiotics followed by gentamicin, cefoxitin, cefepime and ceftazidime for the isolates respectively were sensitive.

In present study, E. coli and Klebsiella have maximum sensitive to nitrofurantoin. Almost all gram negative organisms are very less sensitive to cephlosporin and flouroquinolones groups, Pseudomonas species was found resistant against all commonly used and maximum sensitive was imepenem, meropenem. The results of present study show higher rate of resistance in a private diagnostic laboratory, which may be a result of the irrational use of antibiotics (Dund et al., 2015).

Staphylococcus \& Enterococcus spp. was sensitive to Linezolid (100\%), Vancomycin (94\%). This is comparable with works of Dund et al., 2015. The antimicrobial susceptibility pattern confirms that most of the urinary isolates in our environment are resistant to the commonly used antibiotic including the cephalosporin and fluoroquinolones.

In particular, the high resistance of the gram negative isolates to the fluoroquinolones is worrisome as these are reserve drugs for treating resistance infections (Aderounmu et al., 2006)

\section{Conclusions}

A drug resistance among bacterial pathogen is an evolving process, regular surveillance and monitoring is necessary to provide physicians knowledge on the updated and most effective empirical treatment of UTIs. Periodic reassessment of in vitro susceptibility pattern of urinary pathogens to serve as a guide for antibiotic therapy since these organism exhibit resistances to first-line drugs used for UTI. In order to prevent resistance to antibiotics, the use of antibiotics should be kept under supervision, should be given in appropriate doses for an appropriate period of time.

In the present study, community-acquired UTI and nosocomial UTI were not been distinguished. This was the main limitation of the study.

\section{Conflict of interest}

None to declare.

\section{Acknowledgements}

Authors are very much thankful to honorable Dr. Mostafizur Rahman, Managing Director \& CEO, Popular Diagnostic Centre Ltd., Dhaka-1205 and Md. Shahi Mahmud, Branch Manager, Popular Diagnostic Centre Ltd., Shantinagar, Dhaka-1217 for providing necessary facilities and support.

\section{References}

Akhter S and MH Kabir, 2016. Bacterial isolates and drug susceptibility patterns of urinary tract infection at Shaheed Monsur Ali Medical College. Austin J. Microbiol., 2: 1012.

Aderounmu T, 2006. Catheter associated urinary tract infection: aetiologic agent and antimicrobial susceptibility pattern in Ladoke Akintola University teaching hospital, Osogbo, Nigeria. Afr. J. Biomed. Res., 9: 141-148.

Barber AE, JP Norton, AM Spivak and MA Mulvey, 2013. Urinary tract infections: current and emerging management strategies. Clin. Infect. Dis., 57: 719-724.

Behzadi P, E Behzadi, H Yazdanbod, R Aghapour, MA Cheshmeh and DS Omran, 2010. A survey on urinary tract infections associated with the three most common uropathogenic bacteria. Maedica, 5: 111-115. 
Chakupurakal R, M Ahmed, DN Sobithadevi, S Chinnappan and T Reynolds, 2010. Urinary tract pathogens and resistance pattern. J. Clin. Pathol., 63: 652-654.

Cheesbrough M, 2006. District laboratory practice in tropical countries, part 2, 2nd edition. Cambridge: Cambridge University Press; 2006.

Clinical and Laboratory Standard Institute (CLSI), 2014. Performance standard for antimicrobial susceptibility testing; seventeeth information supplement. CLSI document M100 S17, Clinical and Laboratory Standard Institute Waynne Pennsylvania. 2014.

Alshwaikh RMA, SMA Al-Sorchee, KA Ali and WA Beer, 2014. Antibacterial activity of parsley and cerery aqueous extract on the isolated bacteria from children UTI in Erbil city. 2: 895-903.

Dund JV, R Ninama and M Sinha, 2015. Antibiotic sensitivity pattern of bacteria isolated from catheter associated UTI in a tertiary care hospital, Jamalnagar. Sch. J. App. Med. Sci., 3: 1985-1988.

Gonzalez CM and AJ Schaeffer, 1999. Treatment of urinary tract infection: what's old, what's new, and what works. World Journal of Urology, 7: 372-382.

Hoberman A and ER Wald, 1997. Urinary tract in young febrile children. Pediatr. Infect. Dis. J., 16: 11-17.

Iqbal J, M Rahman, MS Kabir and M Rahman, 1997. Increasing ciprofloxacin resistance among prevalent urinary tract bacterial isolates in Bangladesh. Jpn. J. Med. Sci. Biol., 50: 241-250.

Jones RN, KC Kugler, MA Pfaller and PL Winokur, 1999. Characteristics of pathogens causing urinary tract infections in hospitals in North America, results from the sentry antimicrobial survillance program. Diagn. Microbiol. Infect. Dis., 35: 55-63.

Jha N and SK Bapat, 2005. A study of sensitivity and resistance of pathogenic microorganisms causing UTI in Kathmandu valley. Kathmandu University Medical Journal, 3: 123-129.

Mcloughlin TG and MM Joseph, 2003. Antibiotic resistance patterns of uropathogens in pediatric emergency department patients. Academic Emergency Medicine, 10: 347-351.

Yusuf MA, A Begum and CR Ahsan, 2015. Anibiotic sensitivity pattern of gram negative uropathogenic bacilli at a private hospital in Dhaka city. Al Ameen J. Med. Sci., 8: 189-194.

Shaaban MT, HA Ghozlan and MMEI Maghraby, 2012. Susceptibility of bacteria infecting urinary tract to some antibiotics and essential oils. Journal of Applied Pharmaceutical Science, 2: 90-98.

Navaneeth BV, S Belwadi and N Suganthi, 2002. Urinary pathogrns, resistance to common antibiotics: a retrospective analysis. Trop. Doct., 32: 20.

Nerukar A, P Solanky and SS Naik, 2012. Bacterial pathogens in UTI and antibiotic susceptibility pattern. J. Pharm. Biomed. Sci., 21: 1-3.

Oluremi BB, AO Idowu and JF Olaniyi, 2011. Antibiotic susceptibility of common bacterial pathogens in urinary tract Infection in a Teaching Hospital in Southwestern Nigeria. Afr. J. Microbiol. Res., 5: 3658-3663.

Srinivassa H, SC Parija, S Bhattacharya and R Sehgal, 1999. Incidence of ciprofloxacin resistance in urinary isolates. Estern Nepal J. Comm. Dis., 31: 45-47. 